\title{
Antibody-dependent Complement-mediated Cytotoxicity in Sera from Patients with HIV-1 Infection Is Controlled by CD55 and CD59
}

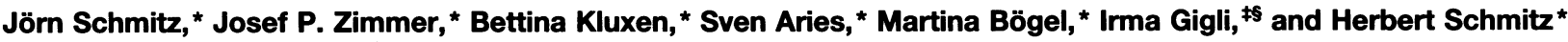

${ }^{*}$ Department of Virology and ${ }^{\ddagger}$ Department of Molecular Biology, Bernhard Nocht Institute for Tropical Medicine, D-20359 Hamburg,

Germany; and ${ }^{8}$ Department of Medicine, Division of Dermatology, University of California, San Diego, California

\begin{abstract}
Various immune mechanisms have been reported to contribute to the progressive destruction of Th cells in HIV-1infected patients. Among these, complement mediated lysis of infected cells has been suggested. An increased sensitivity of lymphocytes from HIV-1-infected patients to lysis by monoclonal antibodies directed to MHC class I antigen and complement has been directly correlated with a decreased expression of the decay accelerating factor (CD55). It also has been reported that the expression of the membrane inhibitor of reactive lysis (CD59) is decreased during HIV-1 infection. We examined the effect of antibodies in the serum of HIV-1-positive individuals and normal human serum (NHS) as source of complement on several HIV-1-infected cell lines differing in their expression of CD55 and CD59. When HIV-1-infected target cells without membrane expression of CD55 and CD59 were used, a highly significant cytotoxic effect was observed in the presence of heat inactivated anti-HIV-1-positive sera and NHS, while heat-inactivated anti-HIV-1-negative sera and NHS were unable to induce cytolysis. Similar results were obtained using purified IgG isolated from HIV-1-positive sera and either NHS or guinea pig serum as source of complement. Lysis of HIV1-infected cells correlated with expression of viral antigens on the cell surface. HIV-1-infected CD55 and CD59 positive target cells showed specific lysis, when the function of these molecules was abrogated by blocking antibodies to CD55 and CD59. The finding of anti-HIV-1-specific cytotoxic antibodies in sera from HIV-1-infected patients should be considered in the pathogenesis of the HIV-1 infection. ( $J$. Clin. Invest. 1995. 95:1520-1526.) Key words: human cell lines • cell lysis • AIDS • complement receptor • HIV immunology
\end{abstract}

J. Schmitz and J. P. Zimmer made equal contributions to the work presented.

Address correspondence to Dr. Herbert Schmitz, Department of Virology, Bernhard Nocht Institute for Tropical Medicine, Bernhard Nocht Str. 74, D-20359 Hamburg, Germany. Phone: 040-31182-460; FAX: 040-31182-386.

J. Schmitz's present address is Department of Medicine, Division of Viral Pathogenesis, Harvard Medical School, 330 Brookline Avenue, Beth Israel Hospital, Boston, MA 02215.

Received for publication 21 November 1994 and accepted in revised form 16 May 1995.

J. Clin. Invest.

(C) The American Society for Clinical Investigation, Inc. 0021-9738/95/09/1520/07 \$2.00

Volume 96, September 1995, 1520-1526

\section{Introduction}

Infection of $\mathrm{CD}^{+}$lymphocytes and monocytoid cells with HIV-1 is one of the most significant findings in AIDS (1). Although neutralizing antibodies directed to the major viral glycoproteins have been described in infected individuals (2), the role of anti-HIV-1 antibodies in the pathogenesis of AIDS is still subject of discussion (3). In addition to neutralizing antibodies, antibody-dependent cellular cytotoxicity against virus-infected cells has been suggested as a potential inhibitor of viral spread (4-7).

A number of studies on the interaction between human complement and viruses have been performed. Whereas Oncornaviruses $(8)$ and RNA tumor viruses $(9,10)$ activate complement and undergo lysis, inactivation or lysis of HIV-1 by normal human serum (NHS) ${ }^{1}$ has not been observed (11) although complement activation does occur in the absence of anti-HIV1 antibodies (12-15). HIV-1 appears to activate the classical pathway directly (16) and recent data demonstrating complement activation as a result of binding of C1q to gp160 support this finding (17). In contrast, increased neutralization of virions has been described when HIV-1-specific antibodies and complement are used. In this reaction, antibodies to the V3 loop of the gp120 of HIV-1 are particularly effective in inducing complement activation and lysis of the virions (18).

In addition to complement activation by virions, virus-infected cells might also activate complement (19-21). Activation of the classical pathway has been demonstrated using cells coinfected with HIV-1 and HTLV-1 but not with cells infected with HIV-1 alone $(22,23)$. Lysis of HIV-1 -infected U937 or KE37 cells has been observed with some sera from HIV-1infected individuals $(24,25)$. Sera from HIV-1-infected chimpanzees and goats immunized with gp120 also contained cytolytic activity (26). In contrast, several groups have been unable to demonstrate lysis of HIV-1-infected human cell lines using anti-HIV-1 positive sera from infected individuals and human complement $(5,7,26)$.

Normal host cells are protected from the lytic action of homologous complement by membrane proteins that strictly regulate the activation and deposition of complement proteins. The membrane proteins complement receptor 1 (CR1 or CD35) (27), membrane cofactor protein (MCP or CD46) (28), and decay accelerating factor (DAF or CD55) (29), induce the dissociation of the $\mathrm{C} 3$ convertases, thus preventing further activation of complement. In addition CD35 and CD46 act as cofactors for C3b cleavage by the serum enzyme factor $I(27,28)$.

1. Abbreviations used in this paper: NHS, normal human serum; PIPBS, propidium iodide phosphate-buffered saline; PI, propidium iodide; MgEGTA, $\mathrm{MgCl}_{2}$-EGTA; CR1, complement receptor 1 or CD35; $\mathrm{MCP}$, membrane cofactor protein or CD46; DAF, decay-accelerating factor or CD55; MIRL, membrane inhibitor of reactive lysis or CD59. 
The membrane inhibitor of reactive lysis (MIRL or CD59) (30-32) and homologous restriction factor (HRF) (33) are two membrane proteins that prevent the assembly of the membrane attack complex (C5b-9). A decreased expression of CD55 and CD59 has been demonstrated on the membrane of lymphocytes of HIV-1-infected patients $(34,35)$. This observation appears to be related to the increased sensitivity of lymphocytes from these patients to the lytic action of complement when cells were sensitized with anti-MHC class I monoclonal antibody (34).

Using several $\mathrm{T}$-cell lines that differ in the expression of the complement regulatory proteins, CD55 and CD59, we have undertaken an evaluation of the role of these proteins in the lysis of HIV-1-infected cells sensitized with serum from HIV1 -infected subjects.

\section{Methods}

Cells and viruses. The HIV-1 virus strain $\mathrm{HTLV}-\mathrm{III}_{\mathrm{B}}$ was replicated in the human permanent cell lines H9, KE37 (H9 subclone), U937, Molt4 and CEM. The uninfected and HIV-1-infected cells were cultured in RPMI 1640 medium supplemented with $10 \%$ heat-inactivated FCS, 100 $\mathrm{U} / \mathrm{ml}$ penicillin, and $100 \mu \mathrm{g} / \mathrm{ml}$ streptomycin (all from Gibco, Eggenstein, Germany). Cells were kept in culture for eight weeks after infection and they were propagated twice weekly. These cell lines were free of mycoplasma as demonstrated by ELISA (Mycoplasma Detection Kit; Boehringer Mannheim, Mannheim, Germany) and electron microscopy. To obtain a maximum number of optimal target cells for lytic assays we compared the presence of intracellular HIV-1 antigens and the expression of HIV-1 antigens on the cell surface by FACS analysis using HIV-1 -specific indirect immunofluorescence (FACScan; Becton Dickinson, Mountain View, CA).

Sera. Serum samples were obtained from 50 patients at different stages of HIV-1 infection. The diagnosis of HIV-1 infection was confirmed by immunofluorescence and Western blot of serum samples. The clinical status of 25 patients was characterized following the CDC classification $(\mathrm{CDC}$ II = asymptomatic infection, $\mathrm{CDC}$ III = LAS, CDC IV C-E = AIDS). Negative control sera were obtained from 50 healthy seronegative individuals at no risk of infection (age: 20-55). Complement activity was inactivated in the serum samples by incubation for one hour at $56^{\circ} \mathrm{C}$ and the sera were stored in small aliquots at $-70^{\circ} \mathrm{C}$. Plasma proteins from $10 \mathrm{HIV}-1$-positive sera and from five HIV-1negative control sera were separated by column chromatography using a Superose B 12 column (Pharmacia, Upsala, Sweden). Pools were made of the IgM, IgG and albumin containing fractions, and the protein concentration of each pool was adjusted to the concentration of the original serum.

NHS used as source of complement was obtained from healthy HIV1 seronegative individuals and kept at $-70^{\circ} \mathrm{C}$ without prior heating at $56^{\circ} \mathrm{C}$. Guinea pig serum was used as a source of heterologous complement. The hemolytic activity of all sera used as source of complement was measured using sensitized sheep erythrocytes. One unit is defined as the dilution resulting in $50 \%$ lysis of $5 \times 10^{8}$ sensitized sheep erythrocytes (36).

Antibodies. Monoclonal antibodies OKT4 and OKT4a (CD4) were purchased from Ortho Diagnostic Systems, Neckargemuend, Germany; IOT 17 (CD35) and IOL 46 (CD46) from Dianova (Hamburg, Germany) WDR 7843 (CD55) from Wako Chemicals (Neuss, Germany); MEM-43 (CD59) from Monosan (Am Uden, The Netherlands). AntiCRI (CD35) monoclonal antibody 543 was previously reported (37). All antibodies mentioned above were used for immunofluorescence staining at a dilution of 1:100. Anti-mouse-FITC $(1: 30)$ and anti-humanFITC, $\mathrm{F}\left(\mathrm{ab}^{\prime}\right)_{2}$ fragments $(1: 30)$ were purchased from Dianova. As control for the indirect immunofluorescence an isotypic mouse IgG antibody was purchased from Becton Dickinson.

For blocking experiments, BRIC 229 (CD59) was purchased from IBGRL (Bristol, Great Britain). It has previously been published that the antibody BRIC 229 does not fix complement (38). An antiserum to CD55 was obtained from rabbits immunized with DAF purified from human erythrocytes $(39) . F\left(a b^{\prime}\right)_{2}$-fragments were prepared by established procedures $(40)$

Immunofluorescence staining. The expression of HIV-1 proteins in the various cell lines was monitored by routine immunofluorescence microscopy using a high titer human anti-HIV-1 serum and FITC antihuman immunoglobulins at a dilution of 1:30 as reported previously (41). Discrimination between total and membrane expression of viral antigens was accomplished by staining the cells either unfixed or after permeabilization of the cell membrane with acetone/methanol.

FACS analysis. Flow cytometric measurements on stained $\mathrm{H} 9$, KE37, U937, Molt-4, and CEM cells were performed using a FACScan (Becton Dickinson) equipped with an argon ion laser running at an extinction line of $488 \mathrm{~nm}$. Logarithmic amplification of fluorescence signals was used. Based on forward light scatter, 10,000 triggered events were counted, and the data were analyzed with the FACScan Lysis II Software Version (Becton Dickinson).

Antibody-dependent complement-mediated cytotoxicity. Cytotoxicity was measured using the ${ }^{51} \mathrm{Cr}$-release assay $(22), 10^{8} \mathrm{HIV}-1$-infected or uninfected $\mathrm{H} 9, \mathrm{KE} 37$, U937, Molt-4 or CEM cells $\left(10^{7}\right.$ cells per ml $)$ were labeled with $100 \mu \mathrm{Ci}$ of sodium chromate $\left({ }^{51} \mathrm{Cr}\right.$ ) (Amersham, Braunschweig, Germany) for $12 \mathrm{~h}$. The cells were washed with RPMI $1640 / 10 \%$ FCS three times $\left(5 \mathrm{~min}, 130 \mathrm{~g}\right.$ ) to remove excess ${ }^{51} \mathrm{Cr}$, and resuspended in RPMI $1640 / 10 \%$ FCS at a concentration of $1 \times 10^{7}$ cells per ml. Equal volumes $(50 \mu \mathrm{l})$ of the labeled cells and dilutions of the heat-inactivated anti-HIV-1-positive serum samples or negative control sera were mixed in 96-well tissue culture plates (Flow Laboratories, Meckenheim, Germany) for $1 \mathrm{~h}$ at $37^{\circ} \mathrm{C}$. NHS as source of complement ( $100 \mu \mathrm{l}$ per well, containing four hemolytic units) was then added, and the culture plates were incubated for another hour at $37^{\circ} \mathrm{C}$. Subsequently, the samples were centrifuged at $130 \mathrm{~g}$ for $5 \mathrm{~min}$ and the radioactivity in $50 \mu \mathrm{l}$ of supernatants was measured in a gamma counter. All experiments were carried out in triplicates. Negative controls included culture medium alone and samples without complement. To measure maximum ${ }^{51} \mathrm{Cr}$-release, a sample of labeled cells was lysed with $200 \mu \mathrm{l}$ Triton X-100 (5\% PBS). In some experiments antibodydependent complement-mediated cytotoxicity was also analyzed by propidium iodide (PI) uptake using flow cytometry. PI was prepared by dissolving $0.05 \mathrm{mg}$ in $100 \mathrm{ml}$ PBS (PI-PBS) as described elsewhere (42). One million cells in $50 \mu$ l RPMI $1640 / 10 \%$ FCS were mixed in Eppendorf tubes with equal volumes of anti-HIV-1-positive serum or controls and NHS as described above. After incubation cells were washed, resuspended in $1 \mathrm{ml}$ of PI-PBS and kept for $5 \mathrm{~min}$ at $4^{\circ} \mathrm{C}$ before FACS analysis. Subsequently, the cells were washed twice in PBS and resuspended in PBS containing $1 \%$ paraformaldehyde.

The percent lysis was determined from ${ }^{51} \mathrm{Cr}$-release as follows:

$\%$ lysis $=\frac{\text { experimental } \mathrm{cpm}-\text { spontaneous } \mathrm{cpm}}{\text { maximum } \mathrm{cpm}-\text { spontaneous } \mathrm{cpm}} \times 100$

Using PI uptake the percent lysis was determined as follows:

\% lysis

$=\frac{\text { experimental PI-stained cells }- \text { spontaneous PI-stained cells }}{\text { number of cells detected by forward light scatter }} \times 100$

The specific lysis produced by a given serum sample is expressed as the lysis of HIV-1-infected cells minus the lysis value of non-HIV1 -infected cells.

To evaluate whether the complement mediated cytotoxicity proceeded via the classical pathway of complement, NHS was incubated with $2.5 \mathrm{mM} \mathrm{MgCl}$ and $10 \mathrm{mM}$ EGTA (MgEGTA) before use. To substantiate the regulatory function of CD55 and CD59 we used blocking antibodies against these surface molecules: BRIC 229 against CD59 and either rabbit IgG or $\mathrm{F}\left(\mathrm{ab}^{\prime}\right)_{2}$-fragments against CD55. As negative control, antibodies to the CD4 antigen were used. 
Table I. Expression of Surface Antigens, HIV-1 Infectivity, and Complement Mediated Lysis of Three Different $\mathrm{CD4}^{+}$Cell Lines

\begin{tabular}{lccccccccc}
\hline & & & & & & & & \multicolumn{2}{c}{ Lysis } \\
\cline { 5 - 8 } & CD4 & CD35 & CD46 & CD55 & CD59 & HIV-1 & Inf. & Uninf. \\
\hline H9 & ++ & - & ++ & + & ++ & ++ & no & no \\
KE37 & ++ & - & ++ & - & - & ++ & no & no \\
U937 & $(+)$ & - & - & - & - & + & yes & yes
\end{tabular}

Expression of surface antigens was determined by immunofluorescence staining using FACS; expression is recorded as: -, negative; $(+)$, weak; + , medium; ++ , strong expression. HIV-1 infection was determined seven days after virus inoculation by indirect immunofluorescence staining of fixed cells. Results are expressed as: $-(<1 \%),+(20-60 \%)$, $++(>60$ positive cells). Lysis of infected (inf.) or uninfected (uninf.) cells by homologous NHS in the absence of anti-HIV-1 serum, yes $(>80 \%)$ and $n o(<5 \%)$ specific lysis.

\section{Results}

H9 and KE37 cells differ in the expression of complement regulatory proteins. $\mathrm{H} 9, \mathrm{KE} 37$, Molt-4, and CEM cells uniformly showed a strong expression of CD4 and CD46 molecules on their membrane. Whereas H9 cells, CEM, and Molt-4 cells, expressed CD55 and CD59, KE37 cells were negative for these two molecules (Table I, Fig. 1). Data for CEM and Molt-4 cells are not shown. U937 cells without phorbol ester stimulation, were weakly positive for CD4, but no expression of CD46, CD55, and CD59 could be found (Table I, Fig. 1). CD35 was not expressed on H9, KE37, and U937 cells (Table I).

All cell lines tested were susceptible to HIV-1 infection, but virus production was delayed in U937 cells (Table I). We attribute this phenomenon to the diminished expression of CD4 molecules (Table I). One week after addition of virus, more than $60 \%$ of $\mathrm{H} 9$ and KE37 cells were infected, while similar

H9
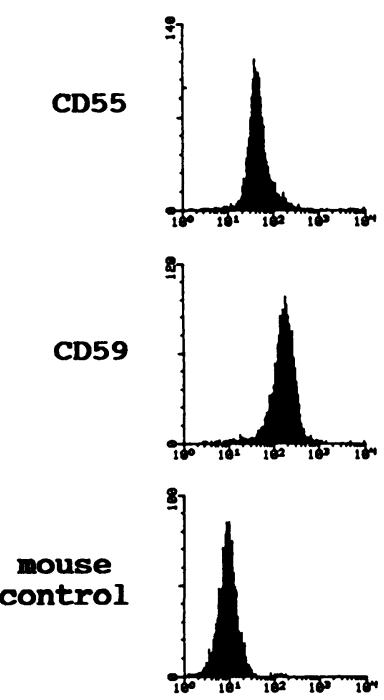

Figure 1. FACS analysis of expression of CD55 and CD59 on noninfected H9, KE37, and U937 cell lines using anti-CD55 and CD59 monoclonal antibodies. For control an isotypic mouse IgG antibody was used.
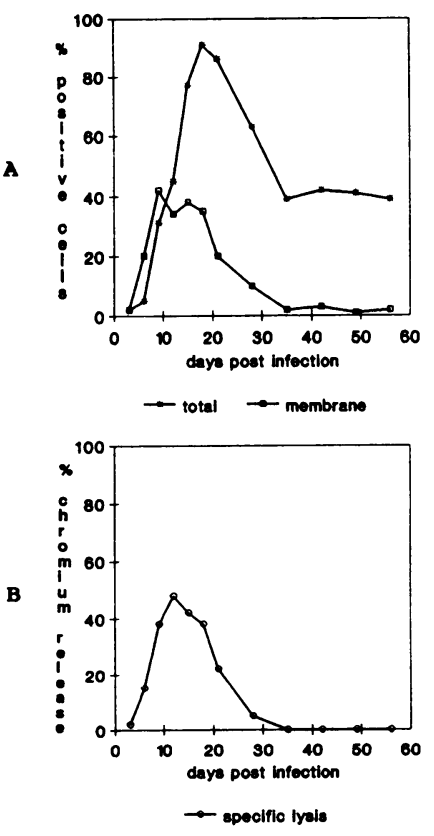

Figure 2. (A) Time course of viral antigen expression determined by FACS analysis on unfixed cells ( $\square$ membrane staining) and on fixed cells (* total fluorescence) following HIV-1 infection $\left(10^{6}\right.$ infectious units of $\mathrm{HTLVIII}_{\mathrm{B}} / 10^{6} \mathrm{KE} 37$ cells, $1 \mathrm{~h}$, $37^{\circ} \mathrm{C}$ ) using serum from a HIV1 -infected individual. Cells maintained in RPMI 1640/10\% FCS. Points shown are means of five determinations per experiment at each time point. Standard deviations were $\leq 10 \%$. $(B)$ Time course of ${ }^{51} \mathrm{Cr}$-release from HIV-1 -infected KE37 cells after exposure to serum from a HIV-1 -infected individual and NHS. The source of anti-HIV-1 serum was the same as above.

values were obtained only after two weeks when U937 cells were used. Infection with HIV-1 did not alter the surface expression of CD46, CD55 or CD59 molecules on H9, KE37, U937, Molt-4, and CEM cells (data not shown).

Kinetics of viral protein expression. After addition of $10^{6}$ infectious units of $\mathrm{HTLV}-\mathrm{III}_{\mathrm{B}}$ to $10^{6} \mathrm{KE} 37$ cells, infection was monitored for eight weeks by indirect immunofluorescent staining using both immunofluorescence microscopy and FACS analysis. Discrimination between total and membrane expression of viral antigens was accomplished by using unfixed and acetone/methanol fixed cells. The results obtained by microscopy were identical to those obtained by FACS analysis. Four days after infection with $\mathrm{HTLV}-\mathrm{III}_{B}$, viral antigens were simultaneously detected on fixed cells (total expression) and on unfixed cells (membrane expression) (Fig. $2 A$ ). On day 21, more than $90 \%$ of the cells were infected, whereas the infection rate dropped to $38 \%$ on day 35 and remained stable at that level until day 60. Expression of viral antigens on the cell surface reached maximum values between days 7 and 18 and decreased to nonsignificant values on day 35 (Fig. $2 \mathrm{~A}$ ). Similar results were obtained using H9, Molt-4, and CEM cells (data not shown).

Human sera contain complement dependent cytotoxic antiHIV-1 antibodies. Initial experiments were performed to determine the susceptibility of the different cell lines with or without HIV-1 infection to the lytic action of complement in the absence of immune serum. No significant lysis of uninfected or infected H9, KE37, Molt-4, or CEM cells occurred, while more than $80 \%$ of the U937 cells were lysed (Table I). Based on these results U937 cells were excluded from the following experiments.

To examine human sera from HIV-1-infected individuals for the presence of antibodies capable of mediating cytotoxicity, 50 HIV-1 antibody-positive human sera and 50 negative control sera were tested using KE37 cells infected with the HTLV$\mathrm{III}_{\mathrm{B}}$ isolate of HIV-1. All sera containing antibodies to HIV-1mediated cytotoxicity in the presence of NHS used as complement source. When KE37 cells with maximum expression of 
Figure 3. Specific lysis of HTLV-III ${ }_{B}$-infected KE37 cells using sera from HIV-1-positive individuals and NHS. (a) Sera with antibodies to HIV-1 $\left({ }^{51} \mathrm{Cr}\right.$ release), mean release $36 \pm 9 \%$, $n=50 ;(b)$ sera with antibodies to HIV-1 (PI uptake) mean uptake $28 \pm 7 \%, n=50$; (c) IgG fractions of positive sera with antibodies to HIV-1 (PI uptake) mean uptake $27 \pm 6 \%, n=10$; negative controls as assessed by $(d){ }^{51} \mathrm{Cr}$-release and $(e) \mathrm{PI}$ uptake; $(f)$ PI uptake after addition of MgEGTA to HIV-1positive sera and NHS ( $n$ $=12$ ).

viral antigens on their surface were used as target cells, the specific ${ }^{51} \mathrm{Cr}$-release ranged from $15 \%$ to $58 \%$ with a mean release of $36 \%( \pm 9 \%$ ) (Figs. $2 B$ and 3 ). The 50 HIV-1negative control sera showed a ${ }^{51} \mathrm{Cr}$ release of $1.8 \%( \pm 0.7 \%)$. The difference between positive and negative sera was highly significant (Wilcoxon Signed Rank $P<0.001$ ). Medium alone and NHS controls showed a background spontaneous lysis of 3.5 and $3.7 \%$, respectively. Maximal lysis of infected cells was observed between days 7 and 28 after infection, when expression of viral antigens on the cell surface reached peak values (Fig. 2, $A$ and $B$ ). Cytotoxic activity dropped to nonsignificant values with decreased expression of viral antigens on the cell membrane although intracellular expression remained at high levels for several weeks after infection ( $>40 \%$ of cells positive by immunofluorescent staining) (Fig. 2, $A$ and $B$ ). These experiments demonstrate that the cytolytic activity in serum of HIV1 -infected individuals in the presence of complement is dependent on the expression of viral antigens on the cell membrane.

FACS analysis of PI-stained cells was also used to assess cytotoxicity (Fig. 4). When compared to ${ }^{51} \mathrm{Cr}$-release, PI uptake yielded somewhat lower values with a mean value of $28 \%$ $( \pm 7 \%)$ and individual lysis ranging from 10 to $52 \%$ (Fig. 3 ). This lower value measured by FACS analysis may be due to disruption of cellular membranes and desintegration of DNA resulting in a reduced PI staining. Similar PI uptake with a mean lysis $27 \%( \pm 6 \%)$ was obtained when the IgG fractions of $10 \mathrm{HIV}-1$-positive sera were analyzed (Fig. 3 ). The IgM

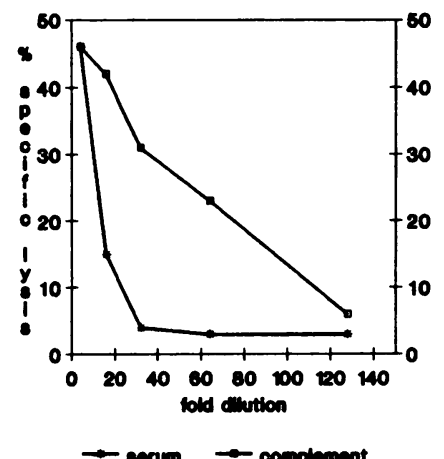

Figure 5. Specific lysis of KE37 cells in the presence of dilutions of a HIV-1-positive serum ( $\square$ ) and a 1:2 dilution of NHS; or in the presence of $1: 4$ dilution of HIV-1-positive serum and dilutions of NHS $(*)$.

and albumin containing fractions, as well as all fractions from HIV-1-negative sera did not cause significant PI uptake.

The utilization of the classical pathway of complement by anti-HIV-1 antibodies was documented by abrogation of the cytotoxic effect upon addition of MgEGTA to the NHS. 12 anti-HIV-1-positive sera causing high PI uptake with NHS as source of complement (mean lysis $32 \%[ \pm 7 \%]$ ) did no longer show cytolytic activity $(<5 \%)$ when MgEGTA was added (Fig. 3). Guinea pig serum diluted 1:10 used as a source of heterologous complement produced similar PI uptake to NHS (mean PI uptake of $31 \%$ [ $\pm 5 \%$ ]), while HIV-1-negative sera produced no significant lysis $(<3 \%)$.

Cytotoxicity was dependent on the concentration of antibody and complement used. Five sera from HIV-1-infected individuals were used in dilution experiments. A representative experiment is shown in Fig. 5. The HIV-1-positive sera used as a source of antibodies could be diluted 1:64. A dilution of 1:16 of complement source drastically reduced cytotoxic activity. When HIV-1-infected H9 (Fig. 6), Molt-4 and CEM cells (data not shown) expressing CD55 and CD59 were used as targets for antibody-dependent complement-mediated cytotoxicity, no significant lysis was observed compared with negative controls suggesting that the absence of the regulatory proteins CD55 and CD59 allow the KE37 cells to undergo lysis in the presence of sera of HIV-1-infected individuals.

Functional effect of blocking CD55 and CD59 using specific antibodies. To clarify the role of CD55 and CD59 in regulation of the lysis of HIV-1-infected cells by serum of HIV-1-infected individuals and complement, H9, Molt-4, and CEM cells that express these regulatory proteins were incubated with antiCD55 or $\mathrm{F}\left(\mathrm{ab}^{\prime}\right)_{2}$-fragments, or anti-CD59 blocking antibodies.

A

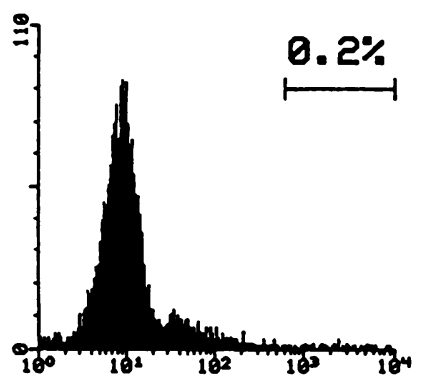

B

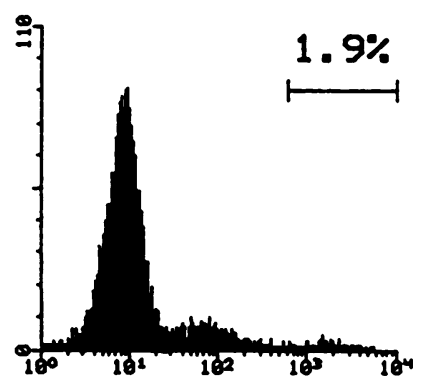

C

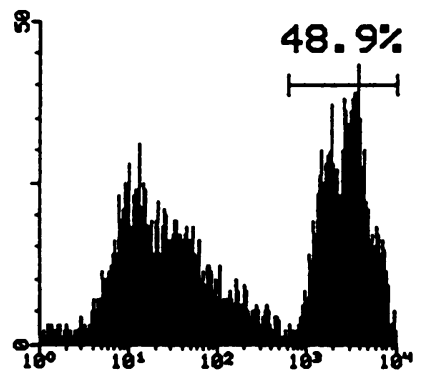

Figure 4. FACS analysis of PI uptake by KE37 cells. The cells were grown for $10 \mathrm{~d}$ after infection with HIV-1 strain HTLV-III . Before the addition of PI the cells were incubated for $1 \mathrm{~h}$ at $37^{\circ} \mathrm{C}$ with: RPMI $1640 / 10 \%$ FCS $(A)$; RPMI $1640 / 10 \%$ FCS and HIV-1 -negative serum (B); RPMI 1640/10\% FCS and HIV-1-positive serum (C). All samples received NHS as source of complement. Histogram $C$ shows a significant increase of dead cells $(48.9 \%)$ as compared to histograms $A$ and $B$ ( 0.2 and $1.9 \%$, respectively). 


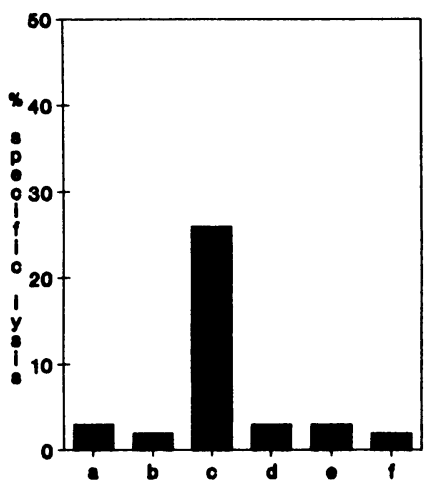

Figure 6. Specific lysis of HIV1-infected $\mathrm{H} 9$ cells as assessed by PI uptake using FACS analysis. (a) HIV-1 - positive sera; (b) HIV-1-negative sera; (c) HIV-1-positive sera after incubation of cells with anti-CD55 and CD59 antibodies; $(d)$ HIV1 -negative sera after preincubation of cells with anti-CD55 and CD59 antibodies; $(e)$ anti-CD55 and CD59 antibodies and cells alone; $(f)$ HIV-1-positive sera after incubation of cells with anti-CD4 antibody. NHS was

added to all samples as source of complement. Anti-CD55 and CD59 antibodies were diluted 1:200.

After incubation, as shown in Fig. 6 and 7 (data not shown for Molt- 4 and CEM cells), the cells were rendered susceptible to lysis by anti-HIV-1 sera and NHS (mean specific lysis $26 \%$ [ $\pm 5 \%]$ ). Similar results were obtained when guinea pig serum was used as source of complement (data not shown). Increasing concentrations of blocking antibodies to CD55 and CD59 showed enhanced lysis in a dose response fashion; the combination of both antibodies led to an increased cytolysis as compared to each antibody alone. Fig. 7 demonstrates a typical dose response histogram of a representative experiment. Antibodies to anti-CD4, another surface determinant without complement regulatory function, did not lead to specific lysis of HIV-1infected or uninfected $\mathrm{H} 9$ or KE37 cells using NHS as complement source (data not shown). Neither anti-CD55 nor antiCD59 antibodies used in these experiments mediated specific lysis in the presence of human (Fig. 6) or guinea pig complement in the absence of anti-HIV-1 sera. No specific lysis was detected after incubation of HIV-1 -infected $\mathrm{H} 9$ cells with antiHIV-1 positive sera and NHS (Fig. 6) or guinea pig complement.

Cytotoxic antibodies are present in all stages of HIV-1 infection. We observed similar values of antibody-dependent complement-mediated cytotoxicity as determined by PI staining in all stages of the disease (CDC II: $28 \%$ [ $\pm 8 \%$ ], CDC III: $32 \%$ [ $\pm 10 \%$ ], CDC IV: $27 \%$ [ $\pm 5 \%]$ ). Absolute numbers of CD4 ${ }^{+}$ cells ranged from 20 to 760 per $\mu$ and CD4/CD8 ratios from 0.08 to 0.88 .

\section{Discussion}

This study demonstrates that sera from HIV-1-infected individuals contain antibodies capable of mediating lysis of HIV-1infected cells in the presence of NHS as source of complement. Cell lysis is dependent on the expression of viral proteins on the cell surface.

In healthy individuals, peripheral blood cells are protected from the lytic action of complement by a number of membrane glycoproteins. During complement activation CD55 prevents amplification of $\mathrm{C} 3 \mathrm{~b}$ deposition by accelerating the decay of the $\mathrm{C} 3$ converting enzymes, $\mathrm{C} 4 \mathrm{~b} 2 \mathrm{a}$ and $\mathrm{C} 3 \mathrm{bBb}$ (27). CD59 binds $\mathrm{C} 8$ and $\mathrm{C} 9$, successfully preventing $\mathrm{C} 9$ polymerization and insertion into the cell membrane $(32,43)$. Lysis of cells bearing CD59 is down regulated when cells and complement are homologous with regard to species, but not when a heterologous source of complement is used (31).

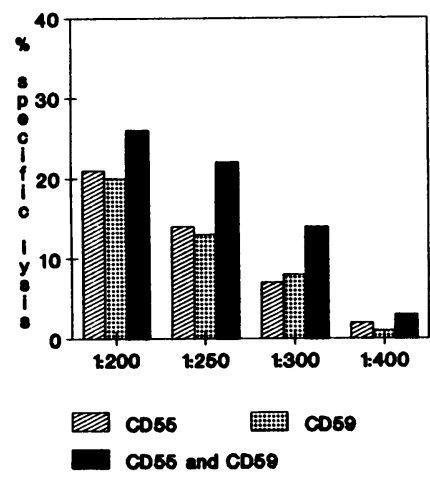

Figure 7. Specific lysis of HIV1 -infected $\mathrm{H} 9$ cells after incubation with dilutions of blocking antibodies to $\mathrm{CD} 55\left(\mathrm{~F}\left(\mathrm{ab}^{\prime}\right)_{2^{-}}\right.$ fragments) and CD59. The antibodies were used individually and in combination. The same anti-HIV-1-positive serum and NHS as source of complement were used in all samples.

The significance of these regulatory proteins on the lytic events induced by anti-HIV-1 antibodies in sera from infected individuals and human complement was demonstrated in our experiments using HIV-1-infected T cells of the line KE37 as targets for antibody-dependent complement-mediated cytotoxicity. These cells do not express CD55 and CD59 on their membranes. All sera from HIV-1-infected patients exhibited cytotoxic activity, while sera from noninfected individuals did not. H9 cells, Molt-4 and CEM that express CD55 and CD59 were resistant to lysis by HIV-1-positive sera and complement. Only by using blocking antibodies to CD55 and CD59, which did not show complement activation, a dose dependent enhancement of antibody-dependent complement-mediated cytotoxicity could be observed. Thus, lysis of HIV-1 -infected cells by antiHIV-1 antibodies and complement is a highly specific and sensitive indicator of HIV-1 infection when the infected target cells lack CD55 and CD59.

Using anti-MHC class I antibodies and complement an enhanced complement sensitivity of lymphocytes from patients with HIV-1 infection has been shown to be related to a diminished expression of CD55 (34) and CD59 on these cells. Incorporation of exogenous CD55 into the lymphocyte membrane ameliorated their abnormal sensitivity to complement (35). Our in vitro findings of complement dependent cytolytic activity of HIV-1 - positive sera on cells lacking CD55 and CD59 provides a possible mechanism for the depletion of $\mathrm{CD} 4{ }^{+}$lymphocytes with reduced expression of these membrane proteins during HIV-1 infection. This concept is further supported by blocking experiments with antibodies to these antigens. Incubation with anti-CD55 and CD59 antibodies rendered formerly resistant HIV-1-infected $\mathrm{H} 9$ cells sensitive to lysis by HIV-1 antibodies and complement.

Contradictory results on the role of antibodies and complement on lysis of HIV-1-infected cells have been published ( 5 , $7,24-26)$. Earlier studies in humans reported the absence of cytotoxic antibodies to HIV-1-infected H9 cells, even though such antibodies could be induced in chimpanzees after infection with HIV-1 or in goats after immunization with purified envelope glycoprotein gp120 $(5,26)$. In the latter experiments, HIV1 -infected H9 cells (26) or gp120-coated CD4-positive lymphocytes, isolated from healthy individuals (5) were used as target cells and heterologous serum (rabbit) as a source of complement. $\mathrm{H} 9$ cells and peripheral lymphocytes express both CD55 and CD59, and are, therefore, not sensitive to lysis by antibody and homologous complement, even though such antibodies might be present in the sera examined. Using HIV-1infected U937 cells and guinea pig sera as a source of comple- 
ment, the presence of specific cytotoxic antibodies has been reported in 15 out of 25 sera from HIV-1-infected individuals (24). Some sera were lytic only after pretreatment of cells with tumor necrosis factor. The U937 cells used in our study do not express CD35, CD46, CD55, or CD59 and are highly susceptible to lysis by NHS even when not infected and in the absence of antibody. U937 cells propagated in different laboratories express a distinct profile of receptors and differ in their response to stimulation by phorbol ester, tumor necrosis factor or varying culture conditions $(44,45)$. Changes in the expression of complement regulating proteins on cell membranes may explain data from our laboratory and others.

The initial event in the infection of human $\mathrm{T}$ lymphocytes by HIV-1 is the attachment of the envelope glycoprotein gp 120 to the CD4 receptor (46). It has been reported that isolated gp120 bound to CD4 on normal lymphocytes may serve as target for antibody dependent cytotoxic attack (5). Antibodies to the V3 region of gp120 are particularly effective in inducing complement activation by HIV-1 (22). Recently, direct activation of complement by rgp120 has been described. This activation, however, did not result in lysis of rgp120-coated CD4 ${ }^{+}$ cells (47). Preliminary experiments in our laboratory indicate that some of the patient sera tested $(3 / 15)$ contain cytotoxic antibodies that recognize the HTLV-III ${ }_{B}$ gp120 and lyse noninfected KE37 cells preincubated with recombinant soluble gp120 (data not shown). In agreement with reported findings (22), our results suggest that epitopes in the hypervariable regions of gp120 might serve as targets for antibody-dependent complement-mediated cytotoxicity. Such restricted antigenic recognition may explain why only a few sera were able to react with the relevant epitopes of $\mathrm{HTLV}-\mathrm{III}_{\mathrm{B}} \mathrm{gp} 120$, while almost all sera tested were cytotoxic when $\mathrm{HTLV}$-III $\mathrm{B}_{\mathrm{B}}$-infected $\mathrm{KE} 37$ cells were used as targets. These findings suggest that besides gp120 additional antigenic sites are recognized by the antibodies in HIV-1-positive serum to produce lysis of infected cells in the presence of complement (25).

Lysis of HIV-1-infected KE37 cells by HIV-1 sera in the presence of complement occurred regardless of the clinical status of the patient, the absolute number of $\mathrm{CD}^{+}$cells or the CD4/CD8 ratio in peripheral blood. The lytic mechanisms leading to the continuous loss of $\mathrm{CD}^{+}{ }^{+}$lymphocytes in vivo over a period of several years may require both a continuous presence of cytotoxic antibodies and a decreased expression of complement regulatory factors.

In conclusion, we have established an experimental model to investigate the effect of cytotoxic antibodies and complement in the course of HIV-1 infection. We detected cytotoxic antibodies against HIV-1-positive cells in all sera from HIV-1-infected individuals. The observation that CD55 and CD59 protect target cells from the lytic action of HIV-1 antibodies and complement explains the contradictory results of other investigators depending on the cell lines used $(5,24-26)$. The complement mediated cytotoxicity of anti-HIV-1 antibodies may contribute to the progressive loss of $\mathrm{CD}^{+}$lymphocytes. Further studies on different $\mathrm{T}$ cell subsets obtained from HIV-1-infected patients are required to provide evidence for the in vivo significance of our findings.

\section{Acknowledgments}

We thank Dr. H. J. Müller-Eberhard for helpful discussions and Mrs. A. Seifert for technical assistance. We thank Dr. H. Sudeck, Dr. J. van
Lunzen, and the staff of the Division of Clinical Medicine, Bernhard Nocht Institute for Tropical Medicine for collecting blood samples. J. Schmitz is a recipient of a fellowship from the German Bundesministerum für Forschung und Technologie AIDS program.

This work was supported by Bundesministerium für Forschung und Technologie grant BGA III-006-89/FVP6, and the National Institutes of Health grant 5 R37 AI20067.

Parts of this study will be presented in the doctoral theses of B. Kluxen.

\section{References}

1. Barré Sinussi, F., C. Axler-Blin, X. Vezinet-Brun, C. Rouzioux, W. Rozenbaum, and L. Montagnier. 1983. Isolation of a T-lymphotropic retrovirus from a patient at risk for acquired immune deficiency syndrome (AIDS). Science (Wash. $D C)$. 220:868-870.

2. Robey, W. G., L. O. Arthur, T. J. Matthews, A. Langlois, T. D. Copeland, N. W. Lerche, S. Oroszlan, D. P. Bolognesi, R. V. Gilden, and P. J. Fischinger. 1986. Prospect for preventation of human immunodeficiency virus infection: purified $120 \mathrm{kDa}$ envelope glycoprotein induces neutralizing antibody. Proc. Natl. Acad. Sci. USA. 83:7023-7027.

3. Broliden, P. A., P. von Gegerfelt, P. Clapham, J. Rosen, E. M. Fenyo, B. Wahren, and K. Broliden. 1992. Identification of human neutralization-inducing regions of the human immunodeficiency virus type 1 envelope glycoproteins. Proc. Natl. Acad. Sci. USA. 89:461-465.

4. Rook, A. H., H. C. Lane, T. Folks, S. McCoy, H. Alter, and A. S. Fauci. 1986. Sera from HTLV-III/LAV antibody-positive individuals mediate antibodydependent cellular cytotoxicity against HTLV-III/LAV infected T-cells. J. Immunol. 138:1064-1067.

5. Lyerly, H. K., T. J. Matthews, A. J. Langlois, D. P. Bolognesi, and K. J. Weinhold. 1987. Human T-cell lymphotropic virus IIIB glycoprotein (gp120) bound to CD4 determinants on normal lymphocytes and expressed by infected cells serves as target for immune attack. Proc. Natl. Acad. Sci. USA. 84:46014605.

6. Ojo Amaize, E. A., P. Nishanian, D. E. Keith, Jr., R. L. Houghton, D. F. Heitjan, J. L. Fahey, and J. V. Giorgi. 1987. Antibodies to human immunodeficiency virus in human sera induce cell-mediated lysis of human immunodeficiency virus-infected cells. J. Immunol. 139:2458-2463.

7. Posner, M. R., H. S. Elboim, T. Cannon, L. Cavacini, and T. Hideshima. 1992. Functional activity of an HIV-1 neutralizing IgG human monoclonal antibody: ADCC and complement-mediated lysis. AIDS Res. Hum. Retroviruses. 8:553-558.

8. Bartholomew, R. M., A. F. Esser, and H.-J. Müller-Eberhard. 1978. Lysis of Oncornaviruses by human serum. J. Exp. Med. 147:844-853.

9. Welsh, R. M., N. R. Cooper, F. C. Jensen, and M. B. A. Oldstone. 1975. Human serum lyses RNA tumor viruses. Nature (Lond.). 257:612-613.

10. Cooper, N. R., F. C. Jensen, R. M. Welsh, and M. B. A. Oldstone 1976. Lysis of RNA tumor viruses by human serum: direct antibody-independent triggering of the classical complement pathway. J. Exp. Med. 144:970-984.

11. Banapour, B., J. Sernatinger, and J. A. Levy. 1986. The AIDS-associated retrovirus is not sensitive to lysis or inactivation by human serum. Virology. 152:268-271.

12. Spear, G. T. 1993. Interaction of non-antibody factors with HIV in plasma. AIDS (Philadelphia). 7:1149-1157.

13. Dierich, W. G., C. F. Ebenbichler, P. Marschang, G. Fürst, N. M. Thielens, and G. J. Arland. 1993. HIV and human complement: mechanisms of interaction and biological implication. Immunol. Today. 14:435-440.

14. Sölder, B. M., T. F. Schulz, P. Hengster, J. Lower, C. Larcher, G. Bitterlich, R. Kurth, H. Wachter, and M. P. Dierich. 1989. HIV and HIV-infected cells differentially activate the human complement system independent of antibody. Immunol. Lett. 22:135-145.

15. Reisinger, E. C., W. Vogetseder, D. Berzow, D. Kofler, G. Bitterlich, H. A. Lehr, H. Wachter, and M. P. Dierich. 1990. Complement-mediated enhancement of HIV-1 infection of the monoblastoid cell line U937. AIDS (Philadelphia). 4:961-965.

16. Ebenbichler, C. F., N. M. Thielens, R. Vornhagen, P. Marschang, G. J. Arlaud, and M. P. Dierich. 1991. Human immunodeficiency virus type 1 activates the classical pathway of complement by direct $\mathrm{Cl}$ binding through specific sites in the transmembrane glycoprotein gp41. J. Exp. Med. 174:1417-1424.

17. Thieblemont, N., N. Haeffner-Cavaillon, L. Weiss, F. Maillet, and M. D. Kazatchkine. 1993. Complement activation by gp160 glycoprotein of HIV-1. AIDS Res. Hum. Retroviruses. 9:229-233.

18. Spear, G. T., B. L. Sullivan, A. L. Landay, and T. F. Lint. 1990. Neutralization of human immunodeficiency virus type 1 by complement occurs by viral lysis. J. Virol. 64:5869-5873.

19. Spear, G. T., A. L. Landay, B. L. Sullivan, B. Dittel, and T. F. Lint. 1990. Activation of complement on the surface of cells infected by human immunodeficiency virus. J. Immunol. 144:1490-1496. 
20. Middeldorp, J. M., J. Jongsma, and T. H. The. 1983. Killing of human cytomegalovirus-infected fibroblasts by antiviral antibody and complement. $J$. Infect. Dis. 153:48-55.

21. Sissons, J. G. P., R. D. Schreiber, L. H. Perrin, N. R. Cooper, H. J. MüllerEberhard, and M. B. A. Oldstone. 1979. Lysis of measles virus-infected cells by the purified cytolytic alternative complement pathway and antibody. J. Exp. Med. 150:445-454.

22. Spear, G. T., D. M. Takefman, B. L. Sullivan, A. L. Landay, and S. Zolla Pazner. 1993. Complement activation by human monoclonal antibodies to human immunodeficiency virus. J. Virol. 67:53-59.

23. Spear, G. T., H. X. Jiang, B. L. Sullivan, H. Gewurz, A. L. Landay, and T. F. Lint. 1991. Direct binding of complement component Clq to human immunodeficiency virus (HIV) and human T lymphotrophic virus-I (HTLV-I) coinfected cells. AIDS Res. Hum. Retroviruses. 7:579-585.

24. Szabo, B., C. Locardi, E. Lo Presti, F. Belardelli, and A. Benedetto. 1993. Tumour necrosis factor-alpha increases the sensitivity of human immunodeficiency virus (HIV)-infected monocytic U937 cells to the complement-dependent cytotoxicity of sera from HIV type 1-infected individuals; role of the gp120 protein. J. Gen. Virol. 74:1271-1276.

25. Gregersen, J. P., S. Mehdi, A. Baur, and J. Hilfenhaus. 1990. Antibodyand complement-mediated lysis of HIV-infected cells and inhibition of viral replication. J. Med. Virol. 30:287-293.

26. Nara, P. L., W. G. Robey, M. A. Gonda, S. G. Carter, and P. J. Fischinger. 1987. Absence of cytotoxic antibody to human immunodeficiency virus-infected cells in humans and its induction in animals after infection or immunization with purified envelope glycoprotein gp120. Proc. Natl. Acad. Sci. USA. 84:3797-3801.

27. Pangburn, M. K. 1986. Differences between the binding sites of the complement regulatory proteins DAF, $\mathrm{CR} 1$ and factor $\mathrm{H}$ on $\mathrm{C} 3$ convertases. $J$. Immunol. 136:2216-2221.

28. Kojima, A., K. Iwata, T. Seya, M. Matsumoto, H. Ariga, J. P. Atkinson, and S. Nagasawa. 1993. Membrane cofactor protein (CD46) protects cells predominantly from alternative complement pathway-mediated C3-fragment deposition and cytolysis. J. Immunol. 151:1519-1527.

29. Nicholson-Weller, A., J. Burge, D. T. Fearon, P. F. Weller, and K. F. Austen. 1982. Isolation of a human erythrocyte membrane glycoprotein with decay-accelerating activity for $\mathrm{C} 3$ convertases of the complement system. $J$. Immunol. 129:184-189.

30. Holguin, M. H., L. J. Fredrick, N. J. Bernshaw, L. A. Wilcox, and C. J. Parker. 1989. Isolation and characterization of a membrane protein from normal human erythrocytes that inhibits reactive lysis of the erythrocytes of paroxysmal nocturnal hemoglobinuria. J. Clin. Invest. 84:7-17.

31. Okada, N., T. Harada, T. Fujita, and H. Okada. 1989. A novel membrane glycoprotein capable of inhibiting membrane attack by homologous complement. Int. Immunol. 1:205-208.

32. Ratnoff, W. D., J. J. Knez, G. M. Prince, H. Okada, P. J. Lachmann, and M. E. Medof. 1992. Structural properties of the glycoplasmanylinositol ancho phospholipid of the complement membrane attack complex inhibitor CD59. Clin. Exp. Immunol. 87:415-421.

33. Zalman, L. S., L. M. Wood, and H. J. Müller-Eberhard. 1986. Isolation of a human erythrocyte membrane protein capable of inhibiting expression of homologous complement transmembrane channels. Proc. Natl. Acad. Sci. USA. 83:6975-6979.

34. Lederman, M. M., S. F. Purvis, E. I. Walter, J. T. Carey, and M. E. Medof. 1989. Heightened complement sensitivity of acquired immunodeficiency syndrome lymphocytes related to diminished expression of decay-accelerating factor. Proc. Natl. Acad. Sci. USA. 86:4205-4209.

35. Weiss, L., N. Okada, N. Haeffner Cavaillon, T. Hattori, C. Faucher, M. D. Kazatchkine, and H. Okada. 1992. Decreased expression of the membrane inhibitor of complement-mediated cytolysis CD59 on T-lymphocytes of HIVinfected patients. AIDS (Philadelphia). 6:379-385.

36. Mayer, M. M. 1961. Complement and complement fixation. In Experimental Immunochemistry. E. A. Kabat and M. M. Mayer, editors. Charles C. Thomas, Springfield, IL. 133-240.

37. Tausk, F. A., A. McCutchan, P. Spechko, R. D. Schreiber, and I. Gigli 1986. Altered erythrocyte C3b receptor expression, immune complexes, and complement activation in homosexual men in varying risk groups for acquired immune deficiency syndrome. J. Clin. Invest. 78:977-982.

38. Rooney, I. A., A. Davis, and B. P. Morgan. 1992. Membrane attack complex (MAC)-mediated damage to spermatozoa: protection of the cells by the presence on their membranes of MAC inhibitory proteins. Immunology. 75:499506.

39. Tausk, F. A., M. Fey, and I. Gigli. 1989. Endocytosis and shedding of the decay accelerating factor on human polymorphonuclear cells. J. Immunol. 143:3295-3302.

40. Hudson, L., and F. C. Hay. 1994. Practical Immunology: Isolation and Structure of Immunoglobins. Blackwell Scientific Publications, Oxford. $281 \mathrm{pp}$

41. Lehr, H. A., J. P. Zimmer, C. Hübner, M. Ballmann, W. Vogel, H. Baisch,

P. Hartter, M. Albani, A. Kohlschlüter, and H. Schmitz. 1990. Decreased binding of HIV-1 and vasoactive intestinal peptide following plasma membrane fluidization of $\mathrm{CD}^{+}$cells by phenytoin. Virology. 179:609-617.

42. Hamelmann, C., B. Foerster, G. D. Burchard, and R. D. Horstmann. 1992. Lysis of pathogenic and nonpathogenic Entamoeba histolytica by human complement: methodological analysis. Parasite Immunol. (Oxf.). 14:23-35.

43. Lachmann, P. J. 1991. The control of homologous lysis. Immunol. Today. 12:312-315.

44. Van den Berg, C. W., O. M. Williams, and B. P. Morgan. 1994. Presence of a dysfunctional form of CD59 on a CD59 ${ }^{+}$subclone of the U937 cell line. Immunology. 81:637-642.

45. Öberg, F., R. Anton, P. Stöckbauer, L. G. Larrson, and K. Nilsson. 1989. Surface antigen expression in human monoblastic U937 cells induced to differentiate and in clones infected with v-myc. In Leucocyte Typing IV. White cell differentiation antigens. W. Knapp, B. Dörken, W. R. Gilks, E. P. Rieber, R. E. Schmidt, H. Stein, and A. E. G. Kr. von dem Borne, editors. Oxford University Press, Oxford. 926-927.

46. Maddon, P. J., A. G. Dalgleish, J. S. McDougal, P. R. Clapham, R. A Weiss, and R. Axel. 1986. The T4 gene encodes the AIDS virus receptor and is expressed in the immune system and the brain. Cell. 47:333-348.

47. Süsal, C., M. Kirschfink, M. Kröpelin, V. Daniel, and G. Opelz. 1994. Complement activation by recombinant HIV-1 glycoprotein gp120. J. Immunol. 152:6028-6034. 